\title{
Walk the Talk? The Effect of Voting and Excludability in Public Goods Experiments
}

\author{
Hans J. Czap, ${ }^{1}$ Natalia V. Czap, ${ }^{1}$ and Esmail Bonakdarian ${ }^{2}$ \\ ${ }^{1}$ Department of Social Sciences (Economics), University of Michigan-Dearborn, 4901 Evergreen Road, Dearborn, MI 48128, USA \\ ${ }^{2}$ Department of Computing Sciences and Mathematics, Franklin University, 201 S. Grant Avenue, Columbus, OH 43215, USA
}

Correspondence should be addressed to Natalia V. Czap, nczap@umich.edu

Received 20 June 2010; Revised 20 October 2010; Accepted 5 November 2010

Academic Editor: Thomas D. Crocker

Copyright ( $) 2010$ Hans J. Czap et al. This is an open access article distributed under the Creative Commons Attribution License, which permits unrestricted use, distribution, and reproduction in any medium, provided the original work is properly cited.

\begin{abstract}
The purpose of this paper is to investigate the effect of voting and excludability on individual contributions to group projects. We conducted two experiments on excludable and nonexcludable public goods, which provided several important results. First, contrary to our expectations, subjects are generally contributing more to the non-excludable compared to the excludable public good. Second, participating in a vote to choose a public project per se makes no difference in contributions. However, if the project that the individual voted for also gets selected by the group, they contribute significantly more to that project. Third, empathy and locus of control are important driving forces of participation in common projects. Our results have implications on the procedural design of obtaining funding for public projects. First, the public should get involved and have a say in the determination of which project should be realized. Second, it might well pay off to attempt to develop a consensus among the population and obtain near unanimous votes, because in our experiment, subjects discriminate between the project they voted for and the project chosen by the majority. Third, the policy proposers should stress the other-regarding interest of the public good rather than just pecuniary incentives.
\end{abstract}

\section{Introduction}

Numerous social and economic problems require group effort and coordination to solve. Many of these situations are characterized by nonrivalry in consumption and nonexcludability. Individuals therefore have the economic incentive to freeride. This is the classical public goods (PGs) problemgiven the economic incentive structure, standard economic theory predicts that the public good will be underprovided, to the detriment of society. One way to alleviate this problem and achieve high contributions is to introduce opportunities for detection and subsequent punishment of freeriders. The efficacy of this approach has been confirmed by the experimental literature (e.g., [1-3]). The problem is, however, that in many public good/common pool resource cases, detection and/or punishment is not straightforward. Examples are international treaties and agreements on global environmental problems (e.g., the 1973 Convention on International Trade in Endangered Species of Flora and Fauna, the 1987 Montreal Protocol on Substances that
Deplete the Ozone Layer, and the 1997 Kyoto Protocol). Not surprisingly, the adherence to these agreements is imperfect [4].

If punishment is not feasible or simple, an alternative way to deal with freeriding is (where possible) to make consumption of the good excludable. Excludable public goods are shared only between people who contributed to their provision. Examples of such goods are neighborhood parks, playgrounds, theatres, cable television, radio-broadcasting in European countries, and so forth. Excludable public goods are similar to club goods [5], but differ in the degree of rivalry.

A number of authors have studied the effect of excludability on contributions to a public good. Cinyabuguma et al. [1] introduced an expulsion mechanism and showed that the threat of expulsion increased contributions. However, it also had a "dark side" (page 1433): it precluded development of reciprocity between the group members and thus cooperation collapsed as soon as the threat was removed. Endogenous excludability was also considered by Croson et al. [6] 
who found that excluding the lowest contributing member from the benefits of a public good raises investment in the voluntary contribution mechanisms and the best-shot mechanisms environments. The paper shows that for this weakest link mechanism to be effective, excludability must be paired with redistribution of the benefits among other members. Fatas et al. [7] provide further support for the positive effect of exclusion on contributions in a study that attaches a probability of being excluded for each player depending on the level of overall contributions.

In a slightly different approach Ahn et al. [8] studied the impact of allowing group members to vote on the exit out of, or entry into the group, with given information on (prospective) members' previous contributions. The authors argue that such an institutional mechanism teaches individuals prosocial behavior and hence increases contributions.

To analyze the importance of exclusivity (in contrast to excludability, which is closer to punishment), Blackwell and McKee [9] designed an experiment in which participants could contribute to a local PG (whose benefits were shared only among members of a subgroup-exclusivity) or to a global PG (whose benefits were shared among the whole group). Contrary to their hypothesis, subjects usually contributed more towards the global PG than to the local PG. This can be partially explained by the differences in return to the two goods.

Generally, Swope [10] found that enforcing exclusion increases contributions to a public good. However, with low-MPCR (marginal per capita return) and a minimum contribution equal to all endowments together, it can also decrease contributions and social welfare. Kocher et al. [11] got less ambiguous results and demonstrated that the efficiency of the provision of voluntary public goods always increases with excludability. However, they also found that the level of contributions is very sensitive to the institutional design, specifically the timing of knowledge of the exclusion threshold.

Even in cases when neither punishment nor excludability is practical in a public good/common pool resource situation, socially suboptimal behavior is not always a problem. Andreoni [12, 13], Andreoni and Miller [14], and Palfrey and Prisbrey $[15,16]$ reason that this is due to other regarding behavior. People do not always maximize their own pecuniary benefits, but instead act altruistically or based on "warm glow". Fehr and Gächter [17] argue similarly that individuals have preferences towards fairness, reciprocity, justice, and commitment. This is supported by Alm et al. $[18,19]$ who provide experimental evidence for the role of reciprocity in the context of tax compliance. Their findings indicate that tax payers reciprocate to behavior by the government as well as tax compliance by fellow citizens. Generally, according to Frey [20], people have an ethical understanding of what is right and wrong and are intrinsically motivated to act accordingly. More pragmatically, Bordignon [21] claims that people by and large treat others the way they want to be treated. Based on this reasoning individuals do, therefore behave socially more optimal than predicted by neoclassical economic theory due to moral and/or ethical considerations.
In addition to, and in combination with, the aforementioned factors, communication has been shown to play a critical role in explaining behavior of subjects in public good and common pool resource problems. For instance, Ostrom et al. [3] show that communication leads to increased cooperation in common-property situations. The more communication was possible the more cooperation increased. Research by Brosig et al. [22] goes further and suggests that interactive, linguistic communication with visible group members is actually required for sustained cooperation. Walker et al. [23] claim that voting also serves as a form of limited communication. They designed a common-pool resource problem in which subjects could propose distributions and subsequently vote on all the proposals submitted. If a rule was adopted, the distribution took place; otherwise subjects decided individually how much they wanted to withdraw from the common pool resource. Their experiment demonstrated that even this limited degree of communication causes efficiency to increase significantly.

Alm et al. [24] look at experimental evidence regarding voting and tax compliance instead. They show that voting on the type of public service received in exchange for tax payment increases tax compliance. In addition, the clearer the vote the higher is compliance. In a related study, Alm et al. [25] consider an experiment with voting on tax, audit and fine rates. Their results again support that the possibility of voting influences tax compliance significantly. The effect can go either way, with a negative vote on increased taxes or enforcement leading to lower tax compliance. Voting seems thus to create a consensus on the appropriate norms in society. Feld and Tyran [26] try to elicit the underlying reasons for the observed impact of voting on fines for tax evasion. In their experiment, contributions/tax compliance increased if fines were voted for (even if only by one individual). The main reason for this is the perceived higher legitimacy of the fine. Furthermore, there is also an element of reciprocity as group members increase their contribution if (a) other group members voted for the same fine (voting is seen as a signal for higher contributions) and (b) other group members are expected to contribute more (the experiment contained an expectation elicitation). Commitment, on the other hand, was shown to be less relevant.

More recently, Kroll et al. [27] designed an experiment estimating the effect of voting on the level of contributions to a public good. Their first treatment contains a binding vote mechanism in which subjects vote on the level of contributions by each group member. The results support that voting significantly increases overall contributions. In the case of a nonbinding vote, instead, contributions turn out to be (marginally) higher initially, but subside quickly in subsequent rounds. Contrary to other studies, Messer et al. [28] found that voting on the type of game to be played had no statistically significant effect on contributions. Only when interacted with cheap talk (subjects were allowed to communicate with each other before the vote) voting had an impact on contributions. Hamman et al. [29] demonstrated that at least some groups achieved high levels of provision by delegating contributions to an elected official. However, even 
in the case of communication, they did not reap all potential benefits from it.

Experiments presented in this paper differ from the past social dilemmas experiments with voting in two aspects. First, all the aforementioned papers have examined voting in the context of either a nonexcludable public good or a common-pool resource. Second, the voting has been either on the rules of enforcement or on the contributions by group members. The only exception is the paper of Alm et al. [24] in which the voting is on the type of public good received in exchange for tax payment. In our paper we are interested, similar to Alm et al. [24], in assessing the effect of voting for the type of public good that should be provided. In contrast to their analysis, however, we (a) do not consider a context of taxation and government and (b) introduce a threshold in the provision of the public good.

Furthermore, we also study if there is a difference in behavior if excludability is introduced. Our design of the excludable public goods game differs from related work discussed above in several aspects including two major ones. First, we use a very low-minimum contribution level (the contribution only has to be above zero). Second, we use a continuous provision point mechanism (with different levels of threshold) in contrast to the voluntary contributions mechanism used in previous experiments. An example of a threshold excludable public good is if a neighborhood decides to construct a new playground. A fixed amount of money is necessary to get the most basic type of playground-the threshold. The quality and the area of the playground (the quality/number of swing sets, slides, and mazes, the type of the sandbox, the lighting, etc.) depend on the amount of money contributed. Higher contributions imply a better playground with higher expected utility for each user (and their parents). A number of authors have employed threshold public good games (e.g., [30-33]). In this paper we are expanding on this literature by introducing thresholds in an excludable public goods game. In addition we analyze in this context the impact of voting (on the size of the threshold and the rate of return) on contributions.

Our experiments provide several important results. First, contrary to our expectations, subjects are generally contributing more to the non-excludable public good compared to the excludable public good. Second, voting to choose a project per se makes no difference in contributions. However, if the project that the individual voted for is also selected by the group, they contribute significantly more to that project. Third, empathy and locus of control are important driving forces of participation in common projects.

The rest of the paper is structured as follows: for each experiment, we first describe the theoretical propositions and experimental design. Next, we present and discuss our results, including the output of an estimation based on an evolutionary algorithm. Finally, we conclude with implications and future development.

\section{Experiment 1: Voting and Excludability}

2.1. Theoretical Propositions. In the non-excludable public good (NPG) setting, subjects have the incentive to free ride by contributing nothing to the common good. Regardless of the size of their contribution, they are still entitled to the same share of the group profits. In order to take advantage from group benefits in the excludable public good (XPG) setting, they have to become a "member" by contributing at least something. We would, therefore expect that subjects will be willing to contribute at least as much in the excludable public good case, because those who do not participate also do not get part of the benefits. For every additional person in the excludable public good scenario that abstains from contribution, the project return for the rest increases (the increase is nonlinear). This leads to our first proposition.

Proposition 1. Average individual contributions, $c$, are at least as high in the excludable public good setting as in the nonexcludable public good setting

$$
c_{X P G} \geq c_{N P G} .
$$

A rejection of this proposition would have very interesting implications as it would indicate that the possibility of excludability puts the good into a different dimension in terms of cooperation and moral obligation. The conclusion would be that subjects are motivated by fairness and equity (inequality aversion) consideration in which similar benefits imply the obligation for similar (fair) contributions.

The second proposition that we are interested in concerns the impact of voting.

Proposition 2. Voting for a project increases individual contributions.

$$
c_{\text {voting }}>c_{\text {no voting. }}
$$

(a) Voting for a project $i \in[A, B]$ increases individual contributions, if that project was actually chosen by the group.

$$
c_{\text {voting ini chosen }}>c_{\text {voting ini not chosen }} \text {. }
$$

(b) Voting for a project with a higher provision point (A) increases individual contribution, if that project was actually chosen.

$$
\mathcal{c}_{\text {voting } A \cap A \text { chosen }}>\mathcal{c}_{\text {otherwise }} \text {. }
$$

Proposition 2 is based on the idea that voting is a form of interaction and socialization that leads subjects to contribute more to the common good. This is different from commitment, which would require that the subject actually voted for the elected project and then maybe felt obliged to act on their vote-this is expressed in Proposition 2(a). Alternatively, voting may indicate an expression of intention. If the majority of subjects voted for the high provision point project, then each individual may expect the average contribution by the other subjects to be higher, which then may cause the subjects to contribute more (a) in order to reciprocate or (b) because the chance of reaching the threshold (provision point) increased. Proposition 2(b) is 
based on similar reasoning as Proposition 2(a), but considers the easier to achieve project as the status quo position. The experiment in this paper does not offer an alternative option for votes, so each subject has to vote for somethingthe low provision point project. Voting for this project then does not have the qualitative implications for behavior as outlined in the explanation for Proposition 2(a). An alternative argument is that the vote for the low provision point project expresses an intention to contribute little. If the project was chosen, this implies that the majority of people in the group are planning to contribute little and hence average as well as individual contributions will be relatively low for this group.

Related to the last argument is the reasoning that a higher threshold also needs higher average contributions to reach. We conjecture, therefore the following.

Proposition 3. Individual contributions to the project with a higher provision point are higher than for the project with a lower provision point.

$$
c_{A}>c_{B}
$$

2.2. Experimental Design. In the beginning of the game, each player receives an endowment of $\$ 10$ which they can keep to themselves or contribute (part or all of it) towards a group project. If the total contribution by the group reaches the (known) provision point, it is multiplied by the rate of return, and divided equally among those who contributed (excludable public goods) or all players (non-excludable public good). In that sense our experiment is a mixture of the traditional provision point mechanism and the voluntary contribution mechanism. The provision points (PP) and the rates of return (RR), given that the provision point is reached, were chosen to fulfill following conditions: $\mathrm{PP}_{\mathrm{A}}>$ $\mathrm{PP}_{\mathrm{B}}, 0<\mathrm{RR}_{\mathrm{B}}<\mathrm{RR}_{\mathrm{A}}$, and $\mathrm{PP}_{\mathrm{A}} / \mathrm{PP}_{\mathrm{B}}=\mathrm{RR}_{\mathrm{A}} / \mathrm{RR}_{\mathrm{B}}$.

The step return ( $\mathrm{SR}$ ) (the $\mathrm{SR}$ is calculated as the group payoff from PG divided by the contribution threshold. This concept was introduced by Croson and Marks [31]. Step return is a measure similar to the concept of marginal per capita return that accounts for the discontinuous nature of the provision point mechanism) was chosen to be equal to 2 for project $\mathrm{A}$, and 1.5 for project $\mathrm{B}$. An SR of 2 is in line with various other experiments (e.g., [31, 34$36]$ ). An SR of 1.5 is at the lower end of SRs (according to Croson and Marks [31, page 242] the SRs range from 1.2 to 9.5), but still above Isaac et al. [32], for instance. Croson and Marks [31] showed in their experiment and in a metastudy that treatments with higher SRs typically receive higher contributions. The experiment in this paper differs from their study, and other papers, in two main dimensions. First, contrary to the traditional provision point mechanism, contributions beyond the threshold yield further return to the group. Second, if the provision point is not reached, $50 \%$ of the contributed funds are returned. In comparison to Croson and Marks [31] the higher provision point increases, compared to the lower provision point, potential reward and risk at the same time. In addition, the setup in this paper removes the cost of overshooting the objective. In that sense
TABLE 1: Summary characteristics of the projects.

\begin{tabular}{lll}
\hline Project & $\begin{array}{l}\text { Provision point } \\
\text { (the project is successful } \\
\text { if the total contributions } \\
\text { reach...) }\end{array}$ & $\begin{array}{l}\text { Rate of return } \\
\text { (if the project is successful, } \\
\text { then the value of contributions } \\
\text { is multiplied by...) }\end{array}$ \\
\hline A & 28 & 2 \\
B & 21 & 1.5 \\
\hline
\end{tabular}

TABLE 2: Experimental conditions.

\begin{tabular}{lccc}
\hline & & $\begin{array}{c}\text { Excludable } \\
\text { Public Good }\end{array}$ & $\begin{array}{c}\text { Nonexcludable } \\
\text { Public Good }\end{array}$ \\
\hline \multirow{2}{*}{ No voting } & Project A & XPG_prjctA & NPG_prjctA \\
& Project B & XPG_prjctB & NPG_prjctB \\
Voting for Project A or Project B & XPG_voting & NPG_voting \\
\hline
\end{tabular}

this experiment is less a game of coordination and resembles more the traditional voluntary contribution mechanism. Adding the risk components assures that, assuming that on average the subjects are not risk-seekers, one project is not strictly superior to the other project. Contributions to public good games are commonly in the range of $40 \%$ to $60 \%$ of the endowment [37]. To ensure, for statistical analysis, sufficient percentages of successful and unsuccessful provision, while keeping the same relative magnitude as the rate of return (see above), the provision points were chosen from the high and the low end of that range (Table 1).

As shown in Table 2, the experiment contains 6 conditions, which will be described in more detail in the next paragraphs: two conditions in which participants are voting for a project $\mathrm{A}$ or $\mathrm{B}$ and then proceed to play a threshold excludable public goods (XPG) and nonexcludable public goods (NPG) game, respectively, and four conditions without voting - excludable and nonexcludable public goods with project $A$ and $B$, respectively.

\subsubsection{Threshold Excludable Public Goods Game with Voting.} The game consists of two stages. During the first stage (voting) subjects are voting for which of the two projectsA or B-they would prefer to be implemented. A simple majority rule is used to determine the outcome of the vote. The results of the vote are displayed to the subjects. During the second stage (contribution), each group member is invited to decide on how much to contribute to the project chosen by the group on stage 1 . If the sum of all contributions equals or exceeds the provision point (threshold), the excludable public good is produced. The profit in the XPG game is then distributed among the group members who contributed to its production. The payoff of each subject, $\pi_{j}$, is determined as.

$$
\pi_{j}= \begin{cases}E-c_{j}+\mathrm{RR}_{i} \frac{\sum_{j=1}^{N} c_{j}}{n}, & \text { if } \sum_{j=1}^{N} c_{j} \geq \mathrm{PP}_{i} \cap c_{j}>0 \\ E-0.5 \cdot c_{j} & \text { otherwise, }\end{cases}
$$


where: $E$ endowment, $c_{j} \in[0, E]$ is the contribution by the $j=1, \ldots, N$ group member, $N$ is the number of players, $n$ is the number of players that contributed to the project, $\mathrm{RR}_{i}$ is the rate of return of the project chosen by the group $i=\mathrm{A}, \mathrm{B}$, and $\mathrm{PP}_{i}$ is the provision point of that project. The level of minimum contributions to the excludable public good was chosen to be simply above zero in order to remove strategic considerations. Even a subject attaching a low probability of success for reaching the provision point will rationally contribute one cent- “just in case”.

2.2.2. Excludable Public Good Game Project A or Project B. In these two conditions, there is no voting stage-the subjects immediately proceed to make contributions to project A or $\mathrm{B}$, respectively, (the type of project is predetermined (Subjects are not aware that the other project exists) ). The payoff of each player is determined in the same fashion as above.

\subsubsection{Threshold Nonexcludable Public Good Game with} Voting. Similar to the excludable public game with voting described above, players select between project A and B during the first stage of each round and then proceed to decide on individual contributions to the project. Rates of return and provision points are the same as in the previous treatment. The benefits of the NPG (if produced) are shared between all group members regardless of their contribution. The participant's payoff is determined as.

$$
\pi_{j}= \begin{cases}E-c_{j}+\mathrm{RR}_{i} \frac{\sum_{j=1}^{N} c_{j}}{N} & \text { if } \sum_{j=1}^{N} c_{j} \geq \mathrm{PP}_{i}, \\ E-0.5 \cdot c_{j} & \text { otherwise }\end{cases}
$$

where $N$ is the number of players in the group (in this game $N=5)$.

2.2.4. Nonexcludable Public Good Game Project A or Project B. The last two conditions are similar to the excludable public good game projects A and B without voting, except the benefits are shared between all 5 group members.

2.2.5. Nash Equilibria. All six conditions have a similar set of Nash equilibria. Any vector of contributions that fulfills following criteria constitutes an efficient Nash equilibrium.
(1) The sum of individual contributions equals the provision point for the respective project.

(2) In the case of the excludable public good game, each individual contribution is larger than zero.

(3) In the case of project B each individual contribution is at most $\$ 6.3$. (The value of $\$ 6.3$ is based on the NPG game or the XPG game with all five players, contributing. In the case of the XPG with only four players, the contributions should be at most 8.25. For three players, there is no feasible maximum contribution consistent with a Nash equilibrium). (In the case of Project A any contribution, including the whole endowment, may represent a Nash equilibrium).

To prove statement (3), assume that the individual has to decide whether to make the pivotal contribution $\left(c_{p}\right)$ (We define a pivotal contribution as the contribution of an individual that, given everyone else's contribution, is sufficient and necessary for the group to reach the provision point) or not. The marginal benefit from making this contribution is given by $=-c_{p}+\mathrm{RR}_{i} \mathrm{PP}_{i} / N$. As long as the marginal benefit is positive the individual should make the pivotal contribution.

For Project $\mathrm{B}$, the marginal contribution turns out to be $\mathrm{MB}=-c_{p}+(1.5 \cdot 22) / 5$, or $\mathrm{MB}=-c_{p}+6.3$. Therefore, it is beneficial for the individual to contribute only if her (pivotal) contribution is at most $\$ 6.3$.

For Project $\mathrm{A}$ the marginal contribution is $\mathrm{MB}=-c_{p}+$ $(2 \cdot 28) / 5$, or $\mathrm{MB}=-c_{p}+11.2$. Hence, it is beneficial for the individual to make a pivotal contribution of up to, and including, her whole endowment of $\$ 10$.

Total contributions higher than the respective provision point are not consistent with a Nash equilibrium, because the individual would be better off reducing her individual contribution for a net gain of $\$ 0.6$ per dollar in case of project $\mathrm{A}$ and $\$ 0.7$ per dollar in case of project B as long as the reduction does not decrease total contributions below the provision point.

In addition to the set of efficient Nash equilibria, each treatment also has an inefficient Nash-equilibrium where all contributions are equal to zero. No player can reach the provision point individually; therefore, the best strategy is to stay in this case with a contribution of $\$ 0$.

Formally the Nash equilibria (NE) are given by:

$$
\mathrm{NE}= \begin{cases}c_{j}, & \sum_{j=1}^{N} c_{j}=\mathrm{PP}_{i} \cap 0<c_{j} \leq 6.3 \cap c_{s}>0 \forall s \in[1,5] \text { for project } \mathrm{B} \text { and } \mathrm{XPG}, \\ c_{j}, & \sum_{j=1}^{N} c_{j}=\mathrm{PP}_{i} \cap c_{j} \leq 6.3 \text { for project } \mathrm{B} \text { and } \mathrm{NPG}, \\ c_{j}, & \sum_{j=1}^{N} c_{j}=\mathrm{PP}_{i} \cap c_{j}>0 \text { for project A and XPG, } \\ c_{j}, & \sum_{j=1}^{N} c_{j}=\mathrm{PP}_{i} \text { for project A and NPG } \\ 0, & \text { otherwise. }\end{cases}
$$


2.3. Experimental Procedures. Two hundred and twenty undergraduate students were recruited as participants. The computerized experiment was administered in an experimental laboratory. It was programmed and run on the software zTree [38]. Subjects were randomly assigned to groups of five people and stayed in their group throughout all 20 rounds of the experiment. Players were not allowed to communicate during the experiment. At the end of the experiment subjects were paid in private in cash according to their earnings in one randomly selected round. To determine the round, one of the participants publicly rolled a 20-sided die. The experiment took on average less than an hour to complete. Average earnings for the experiment were $\$ 18.2$ (the reported hourly wage earnings of about $\$ 8$ can be considered as the opportunity costs of the subjects' time. The average payment of about $\$ 20$ is comparable to other studies (see e.g., [39]), with a standard deviation of \$6.5.

In total, forty four independent groups were run: eight groups for each of the excludable and non-excludable public goods with voting games; seven groups for each of the XPG and NPG without voting with projects A and B. Each subject participated in one session only and was not aware of the results of other groups, so that each of the groups can be considered as an independent observation (the overall results are presented in Appendix A on http:// www-personal.umd.umich.edu/ $\sim$ nczap/Appendices_Walk_ the_Talk.htm).

2.4. Experimental Results. Average contributions by round (Figures 1, 2, and 3) fluctuated in the range of $40 \%-$ $60 \%$ of the endowment with a marginal time-decay of the level of contribution. This is consistent to what was normally observed in previous public goods experiments. In particular, in the multiple-round same-group interactions the contributions start at around $40 \%-60 \%$ of the social optimum and, as more individuals realize the opportunistic opportunities and switch to freeriding, the contributions decline over time (see, for e.g., the surveys of pubic goods experiments by Ledyard [37] and Chaudhuri [40], as well as the papers by Andreoni [12], Cookson [41], Messer et al. [28] among others).

The dynamics of the players' contribution is mixed. In 18 out of 20 rounds of the games with voting the average contributions in the non-excludable public goods scenario were higher than in the excludable public goods (Figure 1). Similarly, in 17 out of 20 rounds of the games with project A the average contributions in NPG stayed above the XPG scenario (Figure 2). Even though in the games with Project B 17 out of 20 rounds had higher contribution to the excludable public good projects (Figure 3), the difference was statistically insignificant.

Overall, participants cooperated more in the nonexcludable public goods scenarios as compared to the excludable public goods scenarios. For games with voting, the mean individual contribution in the NPG game was $\$ 5.62$ which is significantly higher than the $\$ 4.69$ average contributions in the XPG game (Mann-Whitney test,

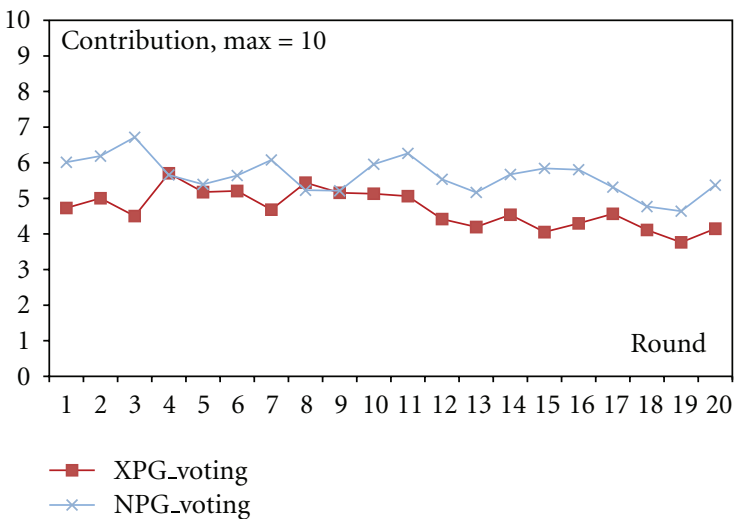

FIgURE 1: Average individual contributions in games with voting (Experiment 1).

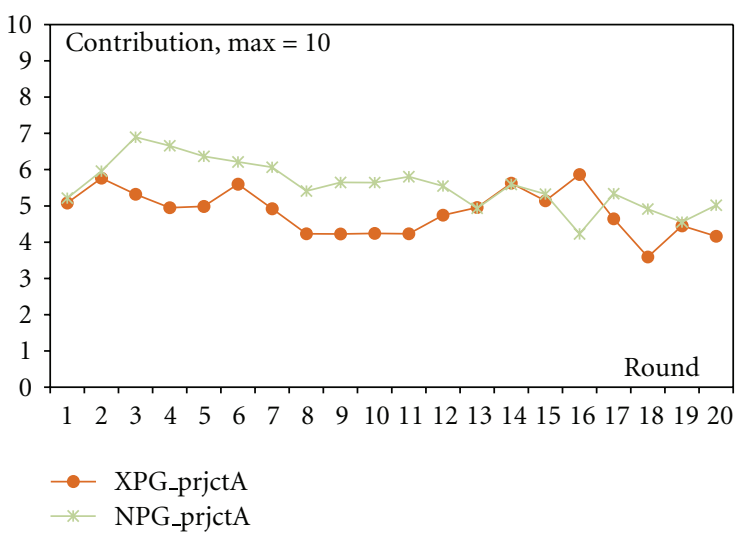

FIgure 2: Average individual contributions in project A games (no Voting, Experiment 1).

$P=.03)$. Similarly, for games without voting with project $A$, the mean individual contribution is significantly higher in the NPG scenario than in the XPG game (Mann-Whitney test, $P=.05)$. At the same time, in case of Project $B$, there is no significant difference between the two scenarios at the $10 \%$-level. Further support for our results is provided by the negative and significant coefficient for the dummy variable ExCludable PG in the regression estimation (Table 3, Model 1).

Another measure of cooperation, the success rate (the proportion of rounds in which a group successfully produced the public good), shows a similar pattern. Success rates are higher in the non-excludable public goods games with voting (Mann-Whitney test, $P=.1$ ) and nonexcludable public goods from project A (Mann-Whitney test, $P=.02$ ) as compared to the respective excludable public goods scenarios. There is no statistically significant difference between the XPG and NPG Project B scenarios. Based on these results we reject the proposition of higher contributions to the excludable public good and conclude that: 


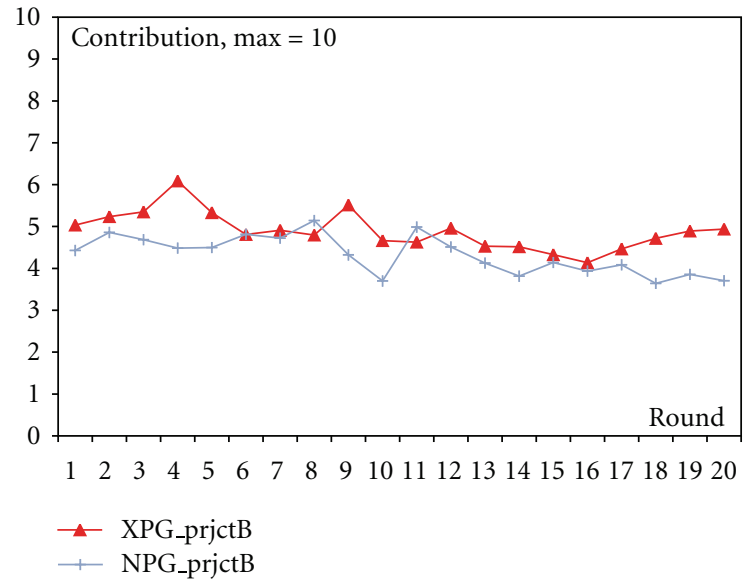

FIGURE 3: Average individual contributions in project B games (no Voting, Experiment 1).

Result 1. Cooperation is higher in non-excludable public good settings than in excludable public good settings.

So, what about the individual propensity to free-ride? There are two tendencies that pull behavior in opposite directions. The first deals with self-interest. In the case of the non-excludable public good, one of the Nash equilibria involves pure freeriding (zero contributions). In case of the excludable public good, however, zero contributions is not a strategy that a neo-classically rational individual would want to pursue, since this strategy will not yield any "extra" profit to the player (which could have been had for just one cent of contribution). The second tendency deals with otherinterest and cooperation. In particular the framing of the NPG game, in which an individual cannot opt out of the benefits of the common good (as in the XPG game), triggers other-regarding behavior-they feel obliged to contribute. The data shows that in general those tendencies cancel each other out in this experiment. There is no significant difference in the level of free-riding between non-excludable and excludable public goods games with voting (MannWhitney test, twosided, $P=.05$ ). In the games without voting there is a difference only for Project B (Mann-Whitney test, two-sided, $P=.02$ ), but not for Project A.

As is apparent from the insignificant coefficient in front of Dummy for Voting (Table 3, Model 1), voting on the type of project to be financed did not affect individual contributions. This can be partially explained by the absence of unanimity in voting: in about $25 \%$ of situations subjects were voting for the project that was not finally selected by a group. Even though voting per se does not seem to matter for average contributions across projects, it may be the case that voters contribute more to projects that they actually voted for individually and that were chosen (Proposition 2(a)). Model 2 (Table 3 ) shows the results from a mixed effects regression of individual contributions on three dummy variables describing the voting of the individual and whether that voting turned out to be successful. The baseline case is a subject voting for Project B while Project A was selected by the majority of the group.
The individual contributions were the highest when a player voted for Project A and A was actually selected by the group: the statistically significant $(P<.01)$ coefficient in front of Voted For A \& A CHOSEn showed that subjects walked their talk and invested on average 42.5 cents more into that project. This is consistent with the conclusions of Swope and Janeba's model [42] that under majority-rule voting the distribution of preferences for a public good is critical in determining both the preferred policy and the level of provision. Voting for a high-return/high-provision point project signals to others one's preferences and could potentially be interpreted as an intention to contribute more. Indeed, those groups who voted for A are more likely to succeed in reaching the provision point (the correlation coefficient is 0.41 for the excludable public and 0.60 for the non-excludable public goods game), than those who voted for B. The individual contributions in the three other situations are not statistically different. However, if one compares the coefficients in front of Voted FOR A \& B CHOSEn and Voted for B \& B CHOSEN, it is apparent that subjects invested relatively (but not significantly: $P=.16$ ) more into Project B when they voted for it. Model 3 (Table 3 ) demonstrates that if the project that a subject was voting for was chosen by the group (variable Voted \& Chosen), they were contributing on average 37.3 cents more to that project. These results provide support for Propositions 2(a) and 2(b), but not for Proposition 2.

Result 2. Individual contributions are higher when the project that a subject voted for was selected by the group, especially when it was the project with the high provision point.

To address Proposition 3, we ran a regression on the group average of individual contributions, with project $A$ as a dummy variable-Dummy Project A (Table 3, Model 1). This variable is evaluated on the basis of group contributions in one round and takes on a value of 1 for non-excludable and excludable public goods with project A (in the voting as well as the no voting condition). The contributions to the project with the higher-return and higher threshold (Project A) were statistically significantly higher than to Project B. This supports our third proposition.

Result 3. Average contributions are higher for the higher provision point project.

At the same time the ratio of average individual contributions $\$ 5.3: \$ 4.6$ is lower than the ratio of the provision points $4: 3(P<.001$, one tail), which means that subjects invested relatively (compared to the provision point) less to Project A. The increase in the provision point (and the rate of return) increases average contributions, but not enough to offset the increase in the provision point. The increase in reward, for Project A is therefore indeed partially offset by the increase in risk.

In addition to the aforementioned propositions, there are several other noteworthy results. First, the regression estimation (Table 4, Model 1) demonstrates that there is 
TABLE 3: The effect of voting and excludability on individual contributions in Experiment 1.

\begin{tabular}{|c|c|c|c|}
\hline Variable & Model $1\left(\mathrm{LS}^{\mathrm{a}}\right)$ & Model 2 (Mixed effects ${ }^{\mathrm{b}}$ ) & Model 3 (Mixed effects ${ }^{c}$ ) \\
\hline Dependent variable & Group average of individual contribution & Individual contribution & Individual contribution \\
\hline Constant & $5.340^{* * *}$ & $5.885^{* * *}$ & $5.925^{* * *}$ \\
\hline Round & $-0.055^{* * *}$ & $-0.057^{* * *}$ & $-0.057^{* * *}$ \\
\hline Excludable PG $($ Yes $=1)$ & $-0.336^{* * *}$ & $-0.884^{* * *}$ & $-0.902^{* *}$ \\
\hline VOTING $($ Yes $=1)$ & -0.093 & & \\
\hline Project A $($ Yes $=1)$ & $0.618^{* * *}$ & & \\
\hline Voted for A \& A CHOSEN & & $0.425^{* * *}$ & \\
\hline Voted for A \& B CHOSEN & & 0.057 & \\
\hline VOTED FOR B \& B CHOSEN & & 0.313 & \\
\hline Voted \& Chosen & & & $0.373^{* *}$ \\
\hline$F$-statistic & 32.3 & & \\
\hline Akaike Info Criterion & & 7531 & 7525 \\
\hline Number of obs. & 880 (44 groups $\times 20$ rounds $)$ & \multicolumn{2}{|c|}{1600 (random effects for 80 subjects) } \\
\hline Conditions & All & \multicolumn{2}{|c|}{ Voting } \\
\hline
\end{tabular}

*** significant at $1 \%$ level, ${ }^{* *}$ significant at $5 \%$ level, ${ }^{*}$ significant at $10 \%$ level.

${ }^{a}$ Least squares estimation with robust standard errors. ${ }^{b}$ Mixed effects model, maximum likelihood estimation. ${ }^{\mathrm{c}}$ Mixed effects model, maximum likelihood estimation.

a time decay of the level of contribution (the coefficient in front of Round variable is negative and significant).

Previous evidence on gender effects in voluntary contribution experiments has been mixed. Whereas, for instance, Solow and Kirkwood [43] and Brown-Kruse and Hummels [44] show larger contributions by men, Seguino et al. [45] find that women instead show higher willingness to contribute to the public good. No significant gender difference is found by Bram Cadsby and Maynes [46], and Andreoni and Petrie [47]. Our experiment shows a strong gender effect in the contributions to the group good. Females contribute almost a dollar more to the non-excludable and excludable public goods than their male counterparts (Table 4, Model 4); when controlled for the round and other treatment parameters, female contribution to the XPG exceeds male contributions to the XPG by 95 cents whereas in the NPG scenario it exceeds by only 67 cents (in the interest of space the full regression is not provided here. The regression can be found in Appendix $B$ on http://www-personal.umd.umich.edu/ nczap/Appendices_ Walk_the_Talk.htm). In a review of the pertinent literature Croson and Gneezy [48] conclude that behavior of females is highly context dependent. Based on their conjecture, our results may indicate that women are more sensitive to the existence of freeriders and interpret the excludable public good design as alleviating this problem-hence contribute more.

Result 4. Females contribute to the group project significantly more than males.

In addition, and in line with previous results by Frank et al. [49], Carter and Irons [50] and Marwell and Ames [51], pursuing an economics major at college decreases the level of cooperation (The overall evidence in the literature on behavior of economics students is mixed. Hu and Liu [52] and Yezer at al. [53], for instance, find that economics students actually cooperate more in certain situations). On average, economic majors contributed to the group project about 80 cents less than other majors. Economics majors also deviate in free-riding from other majors relatively more in the excludable public goods game than in the non-excludable public goods (their contributions were $\$ 1.42$ less in the XPG and only $\$ 0.28$ in the NPG game) (please see Appendix $\mathrm{C}$ provided on http://www-personal.umd.umich.edu/ nczap/Appendices _ Walk_the_Talk.htm). The major effect is the same when we look at the interaction of gender and major. Females with economics training contribute less than other females, but more than males.

Result 5. Economics majors contribute to the group project significantly less than other majors.

\section{Experiment 2: Excludability and the Role of Sequence}

We conducted a second experiment to further investigate (a) whether playing an excludable public good potentially primes subjects and (b) in how far psychological characteristics explain contributions by subjects.

3.1. Theoretical Propositions. The results in the first experiment indicate that there is a fundamental difference between a non-excludable public good and an excludable public good. This then raises the question, whether players are taught different behavior or are put into a different mindset, simply by being exposed to either the XPG or the NPG game. 
TABLE 4: The gender and major effects in Experiment 1.

\begin{tabular}{|c|c|c|c|}
\hline Variable & Model 4 & Model 5 & Model 6 \\
\hline Dependent variable & \multicolumn{2}{|r|}{ Individual contribution } & \\
\hline Female $($ Yes $=1)$ & $0.807^{* * *}$ & \multirow{3}{*}{$-0.790^{* * *}$} & $0.956^{* * *}$ \\
\hline Dummy Economics (Yes = 1) & & & $-0.497^{* * *}$ \\
\hline FEMALE $*$ ECON $($ Yes $=1)$ & & & $-0.666^{* * *}$ \\
\hline Controlled for & & Round, voting, type of project, dummy for playing XPG & \\
\hline Akaike Info Criterion & 21840 & 21837 & 21795 \\
\hline Number of obs. & & 4400 (44 groups $\times 20$ rounds $\times 5$ players $)$ & \\
\hline
\end{tabular}

*** significant at $1 \%$ level, ${ }^{* *}$ significant at $5 \%$ level, ${ }^{*}$ significant at $10 \%$ level.

The first proposition that we are going to test (4th overall) is therefore:

Proposition 4. Playing the excludable or non-excludable public good game changes the subsequent behavior of subjects.

To test for the relevance of psychological factors we focused on three central scales: empathy, trust, and locus of control. The more empathetic a person is the more they are concerned about the well-being of other subjects. This should lead them to be more willing to sacrifice their own monetary benefits for the good of the group. Part of the problem in the typical social dilemma situation is that the behavior of other individuals is not observable ex-ante. The less other subjects contribute the higher the risk that one's own contribution will be wasted and that losses are significant. Assuming riskaverse individuals, trust in other people should therefore lead to increased willingness to contribute more oneself. Lastly, if individuals perceive their own actions as irrelevant in achieving success for the group, they will be less likely to sacrifice their own well-being. Expressed differently, a contribution perceived as pivotal is likely to be higher than an irrelevant one. To summarize, these factors give rise to the following proposition.

Proposition 5. Psychological characteristics are significant determinants of subjects' behavior.

(a) The more empathetic persons are, the more they will invest in the group project.

(b) The more trusting subjects are, the more they will contribute to the public good.

(c) The more individuals believe that their actions significantly influence or determine outcomes, the more they will contribute to the public good.

3.2. Experimental Design. The design of Experiment 2 was largely based on the setup without voting in Experiment 1 . In order to test for a potential framing by an excludable public good compared to a non-excludable public good, we had each subject play both games, with the sequence randomized between groups. Each group of 5 subjects played 10 rounds of one game; then they received a set of new instructions and played 10 more rounds of another game.
A further, minor modification was that we introduced a single provision point and rate of return for this experiment, at $\$ 30$ and 2, respectively. The SR is therefore higher in experiment 2, compared to experiment 1 . Hence, we expect higher average individual contributions, in line with results by Croson and Marks [31] and Result 3. At the end of the experiment we asked demographic questions on major and gender, and, different from experiment 1 , questions to assess empathy, trust, and locus of control.

To measure empathy and trust we used the respective scales from the International Personality Item Pool inventory [54]. The statements for the locus of control scale were drawn from the test developed by Pettijohn [55], which is based on the Internal-External Locus of Control Scale introduced by Rotter [56]. Each of the three personality scales contained several statements (the statements used for each personality scale are available from the authors upon request). The participants were asked to indicate how much they agree with each statement on the scale, ranging from "Completely Agree" (assigned the value of 7) to "Completely Disagree" (assigned the value of 1). The participant's score on each of the three personality scales was calculated as the mean of values she chose for each statement.

3.3. Experimental Procedures. One hundred and twenty undergraduate students were recruited to participate in the study. The experimental procedures were the same as in Experiment 1. Average earnings for the experiment were $\$ 23.4$, with a standard deviation of $\$ 6.9$.

In total twenty four independent groups were run: 12 groups which played XPG goods first, and then NPG; and 12 groups that played the games in reversed order. Similar to Experiment 1, each subject participated in one session only and was not aware of the results of other groups, so that each of the groups can be considered as an independent observation (the overall results are presented in Appendix D on http://www-personal.umd.umich.edu/ nczap/Appendices _ Walk_the_Talk.htm).

3.4. Experimental Results. Average contributions by round (Figure 4) fluctuated in the range of $43 \%-72 \%$ of the endowment. We observe that the time-decay was more pronounced in the treatment in which participants played the NPG in rounds $1-10$ and the XPG game in rounds 


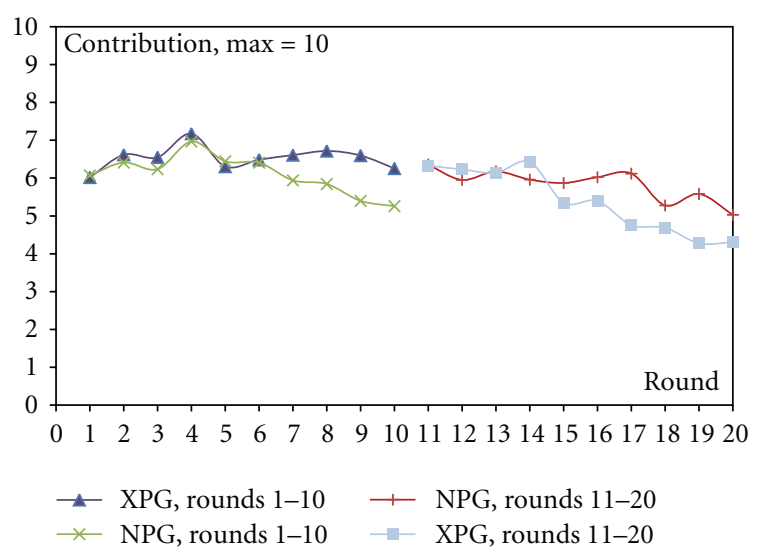

FIgURE 4: Average individual contributions in Experiment 2.

11-20. It is also intriguing that the dynamics of the level of contributions hardly changed after the switch from the excludable to the non-excludable public goods game in round 11. The change from the NPG to the XPG game, however, was very noticeable.

The within-subjects design reduces the variance of the unobserved component (e.g., subject characteristics) and thus increases the precision of the estimated average treatment effect [57]. Normally, randomizing the order at which a treatment is applied (i.e., randomizing the exact sequence: XPG then NPG; NPG, then XPG) helps to eliminate the sequence effect. However, the within-subjects design may suffer from the problem that treatments may interact in unexpected ways. This apparently happened in our game: the subjects were not sensitive to the change from the excludable to the non-excludable public good. However, the effect of switching from the NPG to the XPG game was similar to the effect of restarting the game (see e.g., [41]).

In contrast to Experiment 1, we found that the participants contributed in this experiment more ( $\$ 6.53$ versus $\$ 5.83$ ) in the excludable public goods game if they played it first (Wilcoxon signed-rank test, $P=.05$ ) and in the non-excludable public goods game (\$6.10 versus $\$ 5.39)$ if they played it first (Wilcoxon signed-rank test, $P=.05$ ). Most importantly, playing the XPG game first made a lasting impression on individuals: average contribution in that cohort was $\$ 6.18$ whereas those who started with NPG contributed on average only $\$ 5.74$. Controlling for time decay and the effect of playing excludable public good per se, however, the impact of playing the excludable public good first becomes insignificant (Table 5, Model 7). Proposition 4 is therefore partially confirmed.

Result 6. The sequence of play makes a difference, with excludable public goods sending participants on a higher contribution path.

Out of three psychological traits tested, two-ЕмРATHY and Internal Locus of Control-were shown to significantly affect individual contributions (Table 5, Model
9). This result is consistent with the metaeconomic dualinterest theory [58], experimental findings in the context of environmental public goods [59,60], and speculation in several papers on public goods experiments (e.g., [1, $8,9])$. Proposition 5 is therefore partially supported. The more empathetic a person is, the more she will invest in the group project. Furthermore, the more individuals believe that their actions significantly influence or determine outcomes, the more they contribute to the group good. Hence, these results are in line with Propositions 5(a) and 5(c). There was no relationship found between how trusting an individual is and how much he will contribute-no support for Proposition 5(b).

Result 7. Psychological traits have a significant impact on contributions by individuals. In particular, empathy and locus of control are shown to be important factors.

Similar to experiment 1 , the regression estimation (Table 5, Models 8 and 9) demonstrates time decay in the level of contributions. Subjects invested significantly more in the first 10 rounds (the coefficient of DUMmY FOR ROUNDS $1-10$ is positive and significant) than in the last 10 rounds. Furthermore, gender and economic major were consistent with results from experiment 1, with females contributing significantly more and economic majors significantly less. In addition the results show that subjects majoring in social sciences other than economics (Dummy Social Sciences, Table 5, and Model 7) contributed significantly more than other subjects.

Result 8. Social sciences majors and females contribute significantly more to the group project and economics majors significantly less.

Previous findings (see e.g., $[59,61]$ ) showed that additional information regarding behavior and motivations of individuals in the experiments can be obtained from constructing regressions using a more flexible functional form. In addition to the linear terms in Models 7-9, we may also consider, for example, squared and interaction terms, and decisions in the previous round. Based on only these simple interactions we identified in our data set 230 variables/interaction terms which can be included into the regression (for the complete list of variables please refer to Appendix E on http://www-personal.umd .umich.edu/ nczap/Appendices_Walk_the_Talk.htm). we divided these variables into three sets. Set 1 is the basic set. Set 2.1 includes terms connected to InDIVIDUAL EARNINGS $(-1)$ (a sign of $(-1)$ next to the variable means that the variable is lagged by one round) whereas set 2.2 includes terms connected to Individual Profit From Group Good $(-1)$. Sets 2.1 and 2.2 are highly correlated and therefore cannot be used in the same regression (INDIVIDUAL EARNINGS = ENDOWMENT - INDIVIDUAL CONTRIBUTION TO Group GOOD + Individual Profit From Group Good). Running the regression on all 210 variables (for regressions based on 2.1 and 2.2, resp.) is possible, but highly impractical. We need a subset of these variables for a more 
TABLE 5: The effect of personal traits and major on individual contributions in Experiment 2(mixed effects models, maximum likelihood estimation).

\begin{tabular}{|c|c|c|c|}
\hline \multirow{2}{*}{$\begin{array}{l}\text { Variable } \\
\text { Dependent variable }\end{array}$} & Model 7 & Model 8 & Model 9 \\
\hline & \multicolumn{3}{|c|}{ Individual contribution } \\
\hline Constant & $6.620^{* * *}$ & $5.507^{* * *}$ & $2.507^{* * *}$ \\
\hline ExCludable PG $($ Yes $=1)$ & -0.005 & -0.005 & -0.005 \\
\hline Playing XPG first $($ Yes $=1)$ & 0.439 & & \\
\hline Rounds $1-10($ Yes $=1)$ & & $0.702^{* * *}$ & $0.703^{* * *}$ \\
\hline Round & $-0.083^{* * *}$ & & \\
\hline Female $($ Yes $=1)$ & & $0.340^{* *}$ & $0.458^{* * *}$ \\
\hline ECONOMICs $($ Yes $=1)$ & & $-0.680^{* * *}$ & \\
\hline Social Sciences $($ Yes $=1)$ & & $0.605^{* * *}$ & \\
\hline ЕМРАTHY & & & $0.292^{* * *}$ \\
\hline INTERNAL LoCUS OF CONTROL & & & $0.256^{* *}$ \\
\hline Trust & & & 0.070 \\
\hline Akaike Info Criterion & 12015 & 11970 & 12017 \\
\hline Number of obs. & & 2400 (random effect for 24 groups) & \\
\hline
\end{tabular}

*** significant at $1 \%$ level; **at $5 \%$; at $10 \%$.

useful output and analysis. With 210 terms the number of possible subsets is $2^{210}$ clearly an enormous number of possible combinations. To choose the best subset of terms for the analysis, we used therefore a genetic algorithm as proposed in Bonakdarian et al. [61].

We encoded various subsets of variables as members of our population of potential solutions and, by means of an evolutionary algorithm (in this case, a type of genetic algorithm named $\mathrm{CHC}$ ), evolved this population to ever fitter members over many generations. A genetic algorithm is heavily modeled after the natural process of evolution and is programmed to favor "better" solutions over "worse" ones over time. In our case "better" was defined by smaller variable subsets that were statistically significant. The final population of solutions contained, therefore, mostly subsets that fit these criteria best (for a detailed discussion see Appendix F on http://www-personal.umd .umich.edu/ nczap/Appendices_Walk_the_Talk .htm).

From the output of the genetic algorithm runs we chose respectively the mixed models with random effects for groups (Table 6) with the lowest value for the Bayes information criterion-Model 10 is estimated on the basis of sets 1 and 2.1; Model 11 was estimated using sets 1 \& 2.2. Overall both models provide very similar results and differ in only 4 variables.

The output is not intended to include all relevant variables, but only the most significant ones. This part of the analysis is useful in showing which interactions of variables are particularly important and should be considered on top of the basic models (such as Models 7-9). One key insight from the regressions is that contributions in the past round are among the most important determinants of behavior in the current round. This term shows up by itself as well as in interaction with multiple other variables. Since the coefficient is positive, this indicates that contributions above the average lead to above average contributions in the future as well-there is hysteresis. The hysteresis is particularly strong for women and in cases where the contributions were sufficient to ensure overall success. In these cases the total impact of each dollar of contribution in the past round is to increase contributions this round by more than a dollar. Being empathetic, on the other hand, decreases the impact of past behavior. Interestingly, the opposite takes place with past group contributions. A more empathetic individual reacts positively to higher group contributions. The difference between the reaction of an empathetic person to individual past behavior and group past behavior is intriguing and worth further exploration in future research.

Another interesting result is the effect of including interaction terms into the regression on the coefficient for Female. Whereas in experiment 1 and 2 females were shown to be more willing to contribute to the group good, a more inclusive regression analysis shows that being female actually results in a highly negative effect on levels of contribution. This is tempered by being empathetic or being of a highcontribution-type, but regardless, the overall effect for the terms considered in this regression is negative. In addition to the magnitude and sign of the coefficient it is remarkable that being female shows up as an individual, linear, term as well as in two interaction terms. This shows that gender is also one of the most important determinants of contributions.

As expected, Unfair Contribution(Unfair ContriBUTION is a dummy variable with the value of 1 if an individual did NOT contribute her fair share of the provision point ( $\$ 30 / 5=\$ 6$ ) and 0 otherwise) in the previous round affected current contributions during the first ten rounds negatively. In addition, and consistent with our previous results, there is a time decay of contributions (coefficient on round number is negative). Furthermore, the magnitude of the earnings as expressed by squared terms of INDIVIDUAL EARnings and Individual Profit from Group Good decreases incentives for cooperation. 
TABLE 6: Best results from the genetic algorithm runs for Experiment 2(mixed effects models, maximum likelihood estimation).

\begin{tabular}{|c|c|c|}
\hline \multirow[b]{2}{*}{ Dependent variable } & Model 10 & Model 11 \\
\hline & \multicolumn{2}{|c|}{ Individual contribution } \\
\hline Constant & $3.102^{* * *}$ & $4.149^{* * *}$ \\
\hline Round & $-0.078^{* * *}$ & $-0.075^{* * *}$ \\
\hline Individual Contribution $(-1)^{a}$ & $0.990^{* * *}$ & $0.872^{* * *}$ \\
\hline $\operatorname{SuCCESS}^{b}(-1)($ Yes $=1)$ & & $1.489^{* * *}$ \\
\hline Female $($ Yes $=1)$ & $-3.076^{* * *}$ & $-3.279^{* * *}$ \\
\hline Freshman $($ Yes $=1)$ & $-9.241^{* * *}$ & $-9.239^{* * *}$ \\
\hline Grew up in Urban Area (Yes $=1)$ & $-3.842^{* * *}$ & $-3.858^{* * *}$ \\
\hline Playing XPG first* Social Sciences $($ Yes $=1)$ & $0.800^{* * *}$ & $0.807^{* * *}$ \\
\hline Individual Contribution $(-1) *[$ Success $(-1)($ Yes $=1)]$ & $0.223^{* * *}$ & \\
\hline Individual Contribution $(-1) *$ [Female $($ Yes $=1)]$ & $0.127^{* * *}$ & $0.136^{* * *}$ \\
\hline Individual CONTRIBUtion $(-1)^{*}$ EMPATHY & $-0.142^{* * *}$ & $-0.137^{* * *}$ \\
\hline Group Contribution $(-1) *$ Empathy & $0.016^{* * *}$ & $0.014^{* * *}$ \\
\hline Unfair Contribution $(-1)^{*}[$ Rounds $1-10($ Yes $=1)]$ & $-0.605^{* * *}$ & $-0.583^{* * *}$ \\
\hline$[\text { Female }(\text { Yes }=1)]^{*}$ EMPathy & $0.559^{* * *}$ & $0.587^{* * *}$ \\
\hline ECONOMICS* SENIOR $($ Yes $=1)$ & $-0.436^{* * *}$ & $-0.431^{* * *}$ \\
\hline Social Sciences* Grew up in Urban Area $($ Yes $=1)$ & $-1.254^{* * *}$ & $-1.215^{* * *}$ \\
\hline [Freshman $($ Yes $=1)]^{*}$ Internal Locus of CONTRoL & $2.087^{* * *}$ & $2.085^{* * *}$ \\
\hline [Grew up in Urban Area $($ Yes $=1)]^{*}$ Parent Education & $0.865^{* * *}$ & $0.864^{* * *}$ \\
\hline INDIVIDUAL EARNINGS $(-1)$ SQUARED & $-0.013^{* * *}$ & \\
\hline INDIVIDUAL EARNINGS FROM GROUP PROJECT $(-1)$ SQUARED & & $-0.009^{* * *}$ \\
\hline Akaike Info Criterion & 10233.46 & 10233.67 \\
\hline Bayes Info Criterion & 10347.94 & 10348.15 \\
\hline Log Likelihood & 5096.73 & 5096.84 \\
\hline Number of obs. & \multicolumn{2}{|c|}{2400 (random effect for 24 groups) } \\
\hline
\end{tabular}

a The sign $(-1)$ next to a variable means that the variable is lagged by one round.

${ }^{\mathrm{b}}$ SuCCESs is a dummy variable with the value of 1 if the group contribution reached the provision point and 0 otherwise.

We also find that Freshman in general cooperate much less, but those with high levels of internal locus of control cooperate relatively more. So staying in college for more than a year (being engaged in teamwork, athletics, and living away from the family) teaches cooperation. Socialization seems to work for all but economics students: ECONOMICs*SENIOR is negative. Finally, maybe not surprisingly, growing up in an urban area (as compared to rural area) mostly negatively affects cooperation.

Result 9. Inclusion of interaction terms and past decisions into the regression using a genetic algorithm significantly enriches our understanding of the determinants of cooperation in group projects. In particular contributions in the previous round and gender were found to be among the most important determinants of individual contributions.

\section{Conclusions and Future Research}

In this paper, we presented the results from two experiments. The first experiment was designed primarily to test whether there is a significant difference in contributions (a) between an excludable and a nonexcludable public good, (b) if voting on the type of project to be undertaken is introduced, and (c) if the provision point and rate of return change. The second experiment examined more closely the difference between an XPG and NPG in terms of (a) the relevance of sequence of play and (b) the importance of psychological traits in explaining behavior by subjects.

Contrary to our expectations our findings support that individuals are actually more inclined to contribute to a nonexcludable public good than to an excludable public good. This result is overall consistent with the low-MPCR treatments of Swope [10]. However, given that we had a very low minimum contributions cutoff, this is somewhat surprising, because one may expect that people would be happier to give to a common cause if free riding is discouraged. We explain this result by the higher "moral" obligation to contribute if one also benefits. In this sense, excluding nonmembers from consumption crowds out other-oriented behavior. This resembles to some degree the crowding out of donations through pecuniary benefits as observed, for example, in the context of blood donors $[62,63]$. This explanation also echoes Blackwell and McKee [9, page 129] 
who speculate that "some combination of reciprocity and altruism causes the perceived returns to the local (local public good is restricted to the member of a particular sub-group (assigned randomly), whereas global public good include the whole group) and global public goods to differ sharply". A policy implication of this is that a potentially excludable good should be either financed completely through member fees (i.e., not relying on additional contributions), or made publicly available and financed through voluntary public contributions.

Our experiment shows that voting per se does not significantly increase contributions. However, individuals who voted for the project that was chosen (in particular in case of the more difficult to finance good) did walk the talk and invested more. This has implications on the procedural design of obtaining funding for public projects. First, the public should get involved and have a say in the determination of which project should be realized. Second, it might well pay off to not rely on majority votes only, but rather attempt to develop a consensus among the population and obtain near unanimous votes, because in our experiment subjects discriminate between what project they voted for and what project was actually chosen by the majority.

Lastly, the first experiment shows that people rise to the occasion. If a higher provision point is introduced together with a higher rate of return people are motivated to contribute more. However, we observed that the percentage increase in contributions does not correspond to the percentage increase in the provision point. This implies that the size of public projects can be increased, as long as the rate or return increases as well, but that there are limits to by how much.

From experiment 2, we want to highlight in particular our results on the importance of psychological traits for individual contributions to a public good. Both, empathy and locus of control have been shown to be highly significant in explaining contributions. This is in line with the idea of a dual-interest [58] for the individual in the social dilemma situation: people typically display other regarding behavior as well as self-interest when dealing with these types of social dilemmas. Our result also fits to the conjectures of Blackwell and McKee [9] and Cinyabuguma et al. [1] that cooperation in (even excludable) public goods environments cannot be explained solely by the institutional design of such environment, but also by other-regarding preferences, including reciprocity and altruism. Talking about the benefits to the group or the benefits to other individuals may nudge people into feeling more empathetically and hence increase their willingness to contribute. Similarly, making people feel significant in their contribution, giving them the (perceived) status as a pivotal contributor, will lead to significant increases in contributions.

Future research should examine in more details the effect of voting on individual contributions. In particular, it would be useful to consider how voting/choosing a project from the menu of three or more projects affects decisions. It would be also interesting to introduce an opportunity for the group members to discuss the project before voting.
Finally, the projects in our study were different in only two dimensions - the rate of return and the provision point. Future researchers may want to add other dimensions such as different refund rates or, in the case of the excludable threshold public good, an opportunity to exclude a member who contributed less than the fair share of the provision point.

As our experiments showed, personal characteristics significantly affect individual contributions. Therefore, future researchers are urged to form groups not randomly, as it is common in economic experiments, but based on the psychological predispositions and/or voting patterns. In real life groups are often formed based on individual interests, thus those self-selected groups are intrinsically motivated to sustain higher levels of cooperation than those which are formed randomly. In addition (or instead), one may incorporate Tiebout's voting-with-their-feet by allowing participants to switch to another group with different contribution standards if they are not satisfied with the results of voting or contributions in their own group.

\section{Acknowledgments}

The experiments were conducted when H. Czap and N. Czap were working at St. Lawrence University. Research grants provided by SLU are gratefully acknowledged. The authors appreciate the assistance of several students: John Slattery, Julia Darcy, Brent Davis, and Kim Le in collecting the data. This paper benefited from the comments of the participants of the SEA meeting in New Orleans, LA and research seminars at St. Lawrence University and Florida Atlantic University. This work was supported in part by an allocation of computing time from the Ohio Supercomputer Center. H. Czap and N. Czap thank their colleague Professor. Michael Twomey for his comments on our paper. The authors also want to thank the editor and anonymous reviewers for their helpful suggestions. The usual caveats apply. H. J. Czap, N. V. Czap, and E. Bonakdarian are contributed equally to the project.

\section{References}

[1] M. Cinyabuguma, T. Page, and L. Putterman, "Cooperation under the threat of expulsion in a public goods experiment," Journal of Public Economics, vol. 89, no. 8, pp. 1421-1435, 2005.

[2] D. Masclet, C. Noussair, S. Tucker, and M. C. Villeval, "Monetary and nonmonetary punishment in the voluntary contributions mechanism," American Economic Review, vol. 93, no. 1, pp. 366-380, 2003.

[3] E. Ostrom, J. Walker, and R. Gardner, "Covenants with and without a sword: self-governance is possible," American Political Science Review, vol. 86, no. 2, pp. 404-417, 1992.

[4] N. Choucri, "Political economy of the global environment," International Political Science Review, vol. 14, no. 1, pp. 103$116,1993$.

[5] J. M. Buchanan, "An economic theory of clubs," Economica, vol. 32, no. 125, pp. 1-14, 1965. 
[6] R. Croson, E. Fatas, and T. Neugebauer, "Excludability and contribution: a laboratory study in team production," Working Paper, University of Texas-Dallas, 2006.

[7] E. Fatas, A. J. Morales, and P. Ubeda, "Blind justice: an experimental analysis of random punishment in team production," Journal of Economic Psychology, vol. 31, no. 3, pp. 358-373, 2010.

[8] T. K. Ahn, R. M. Isaac, and T. C. Salmon, "Coming and going: experiments on endogenous group sizes for excludable public goods," Journal of Public Economics, vol. 93, no. 1-2, pp. 336351, 2009.

[9] C. Blackwell and M. McKee, "Only for my own neighborhood? Preferences and voluntary provision of local and global public goods," Journal of Economic Behavior and Organization, vol. 52, no. 1, pp. 115-131, 2003.

[10] K. J. Swope, "An experimental investigation of excludable public goods," Experimental Economics, vol. 5, pp. 209-222, 2002.

[11] M. Kocher, M. Sutter, and V. Waldner, "Exclusion from public goods as an incentive system-an experimental examination of different institutions," Working Paper. University of Innsbruck, 2004.

[12] J. Andreoni, "Cooperation in public-goods experiments: kindness or confusion?" American Economic Review, vol. 85, no. 4, pp. 891-904, 1995.

[13] J. Andreoni, "Warm-glow versus cold-prickle: the effects of positive and negative framing on cooperation in experiments," Quarterly Journal of Economics, vol. 110, no. 1, pp. 1-21, 1995.

[14] J. Andreoni and J. Miller, "Giving according to GARP: an experimental test of the consistency of preferences for altruism," Econometrica, vol. 70, no. 2, pp. 737-753, 2002.

[15] T. R. Palfrey and J. E. Prisbrey, "Altruism, reputation and noise in linear public goods experiments," Journal of Public Economics, vol. 61, no. 3, pp. 409-427, 1996.

[16] T. R. Palfrey and J. E. Prisbrey, "Anomalous behavior in public goods experiments: how much and why?" American Economic Review, vol. 87, no. 5, pp. 829-846, 1997.

[17] E. Fehr and S. Gächter, "Cooperation and punishment in public goods experiments," American Economic Review, vol. 90, no. 4, pp. 980-994, 2000.

[18] J. Alm, B. R. Jackson, and M. McKee, "Estimating the determinants of taxpayer compliance with experimental data," National Tax Journal, vol. 45, pp. 107-114, 1992.

[19] J. Alm, G. H. McClelland, and W. D. Schulze, "Why do people pay taxes?" Journal of Public Economics, vol. 48, no. 1, pp. 2138, 1992.

[20] B. S. Frey, "A constitution for knaves crowds out civic virtues," Economic Journal, vol. 107, no. 443, pp. 1043-1053, 1997.

[21] M. Bordignon, "Was Kant right? Voluntary provision of public goods under the principle of unconditional commitment," Economic Notes, vol. 3, pp. 342-372, 1990.

[22] J. Brosig, J. Weimann, and A. Ockenfels, "The effect of communication media on cooperation," German Economic Review, vol. 4, no. 2, pp. 217-241, 2003.

[23] J. M. Walker, R. Gardner, A. Herr, and E. Ostrom, "Collective choice in the commons: experimental results on proposed allocation rules and votes," Economic Journal, vol. 110, no. 460, pp. 212-234, 2000.

[24] J. Alm, B. R. Jackson, and M. McKee, "Fiscal exchange, collective decision institutions, and tax compliance," Journal of Economic Behavior and Organization, vol. 22, no. 3, pp. 285303, 1993.
[25] J. Alm, G. H. McClelland, and W. D. Schulze, "Changing the social norm of tax compliance by voting," Kyklos, vol. 52, no. 2, pp. 141-171, 1999.

[26] L. P. Feld and J. R. Tyran, "Tax evasion and voting: an experimental analysis," Kyklos, vol. 55, no. 2, pp. 197-222, 2002.

[27] S. Kroll, T. L. Cherry, and J. F. Shogren, "Voting, punishment, and public goods," Economic Inquiry, vol. 45, no. 3, pp. 557570, 2007.

[28] K. D. Messer, H. Zarghamee, H. M. Kaiser, and W. D. Schulze, "New hope for the voluntary contributions mechanism: the effects of context," Journal of Public Economics, vol. 91, no. 9, pp. 1783-1799, 2007.

[29] J. Hamman, R. Weber, and J. Woon, "Experimental investigation of delegation, voting and the provision of public goods," manuscript, 2010.

[30] M. Bagnoli and B. L. Lipman, "Provision of public goods: fully implementing the core through private contributions," Review of Economic Studies, vol. 56, no. 188, pp. 583-602, 1989.

[31] R. Croson and M. Marks, "Step returns in threshold public goods: a meta- and experimental analysis," Experimental Economics, vol. 2, pp. 239-259, 2000.

[32] R. M. Isaac, D. Schmidtz, and J. M. Walker, "The assurance problem in a laboratory market," Public Choice, vol. 62, no. 3, pp. 217-236, 1989.

[33] J. Sonnemans, A. Schram, and T. Offerman, "Public good provision and public bad prevention: the effect of framing," Journal of Economic Behavior and Organization, vol. 34, no. 1, pp. 143-161, 1998.

[34] M. Bagnoli and M. McKee, "Voluntary contributions games: efficient private provision of public goods?" Economic Inquiry, vol. 29, pp. 351-366, 1991.

[35] M. Marks and R. Croson, "Alternative rebate rules in the provision of a threshold public good: an experimental investigation," Journal of Public Economics, vol. 67, no. 2, pp. 195220, 1998.

[36] M. B. Marks and R. T. A. Croson, "The effect of incomplete information in a threshold public goods experiment," Public Choice, vol. 99, no. 1-2, pp. 103-118, 1999.

[37] J. O. Ledyard, "Public goods: a survey of experimental research," in The Handbook of Experimental Economics, J. H. Kagel and A. E. Roth, Eds., pp. 111-194, Princeton University Press, 1995.

[38] U. Fischbacher, "Z-Tree: Zurich toolbox for ready-made economic experiments," Experimental Economics, vol. 10, no. 2, pp. 171-178, 2007.

[39] N. Nikiforakis and H. T. Normann, "A comparative statics analysis of punishment in public-good experiments," Experimental Economics, vol. 11, no. 4, pp. 358-369, 2008.

[40] A. Chaudhuri, "Sustaining cooperation in laboratory public goods experiments: a selective survey of the literature," Experimental Economics. In press.

[41] R. Cookson, "Framing effects in public goods experiments," Experimental Economics, vol. 3, pp. 55-79, 2000.

[42] K. Swope and E. Janeba, "Taxes or fees? The political economy of providing excludable public goods," Journal of Public Economic Theory, vol. 7, no. 3, pp. 405-426, 2005.

[43] J. L. Solow and N. Kirkwood, "Group identity and gender in public goods experiments," Journal of Economic Behavior and Organization, vol. 48, no. 4, pp. 403-412, 2002.

[44] J. Brown-Kruse and D. Hummels, "Gender effects in laboratory public goods contribution. Do individuals put their 
money where their mouth is?" Journal of Economic Behavior and Organization, vol. 22, no. 3, pp. 255-267, 1993.

[45] S. Seguino, T. Stevens, and M. A. Lutz, "Gender and cooperative behavior: economic man rides alone," Feminist Economics, vol. 2, no. 1, pp. 1-21, 1996.

[46] C. Bram Cadsby and E. Maynes, "Gender and free riding in a threshold public goods game: experimental evidence," Journal of Economic Behavior and Organization, vol. 34, no. 4, pp. 603620, 1998.

[47] J. Andreoni and R. Petrie, "Beauty, gender and stereotypes: evidence from laboratory experiments," Journal of Economic Psychology, vol. 29, no. 1, pp. 73-93, 2008.

[48] R. Croson and U. Gneezy, "Gender differences in preferences," Journal of Economic Literature, vol. 47, no. 2, pp. 448-474, 2009.

[49] R. H. Frank, T. D. Gilovich, and D. T. Regan, "Does studying economics inhibit cooperation?" Journal of Economic Perspectives, vol. 7, pp. 159-171, 1993.

[50] J. R. Carter and M. D. Irons, "Are economists different, and if so, why?” Journal of Economic Perspectives, vol. 5, pp. 171-177, 1991.

[51] G. Marwell and R. E. Ames, "Economists free ride, does anyone else?. Experiments on the provision of public goods, IV," Journal of Public Economics, vol. 15, no. 3, pp. 295-310, 1981.

[52] Y. A. Hu and D. Y. Liu, "Altruism versus Egoism in human behavior of mixed motives," American Journal of Economics and Sociology, vol. 62, no. 4, pp. 677-705, 2003.

[53] A. M. Yezer, R. S. Goldfarb, and P. J. Poppen, "Does studying economics discourage cooperation? watch what we do, not what we say or how we play," Journal of Economic Perspectives, vol. 10, no. 1, pp. 177-186, 1996.

[54] L. R. Goldberg, J. A. Johnson, H. W. Eber et al., “The international personality item pool and the future of public-domain personality measures," Journal of Research in Personality, vol. 40, no. 1, pp. 84-96, 2006.

[55] T. F. Pettijohn, Psychology: a connectext, Dushkin/McGrawHill, 4th edition, 1999, Locus of control survey as of November 8, 2009.

[56] J. B. Rotter, "Generalized expectancies for internal versus external control of reinforcement," Psychological Monographs, vol. 80, no. 1, pp. 1-28, 1966.

[57] J. A. List, S. Sadoff, and M. Wagner, "So you want to run an experiment, now what? Some simple rules of thumb for optimal experimental design," NBER Working Paper 15701, 2010.

[58] G. D. Lynne, "Toward a dual motive metaeconomic theory," Journal of Socio-Economics, vol. 35, no. 4, pp. 634-651, 2006.

[59] N. V. Ovchinnikova, H. J. Czap, G. D. Lynne, and C. W. Larimer, "'I don't want to be selling my soul": two experiments in environmental economics," Journal of SocioEconomics, vol. 38, no. 2, pp. 221-229, 2009.

[60] N. V. Czap and H. J. Czap, "An experimental investigation of revealed environmental concern," Ecological Economics, vol. 69, no. 10, pp. 2033-2041, 2010.

[61] E. Bonakdarian, H. J. Czap, and N. V. Czap, "Selection of minimal variable subsets with the help of genetic algorithms in economic analysis," Journal of Interdisciplinary Economics, vol. 21, no. 4, pp. 407-425, 2009.

[62] R. Titmuss, The Gift Relationship: From Human Blood to Social Policy, George Allen and Unwin, London, UK, 1970.
[63] C. Mellström and M. Johannesson, "Crowding out in blood donation: was Titmuss right?" Journal of the European Economic Association, vol. 6, no. 4, pp. 845-863, 2008. 


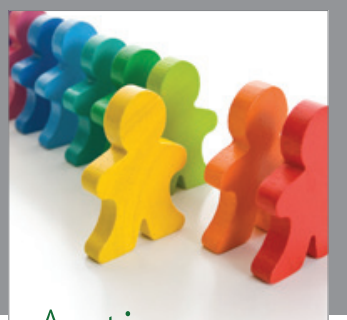

Autism

Research and Treatment
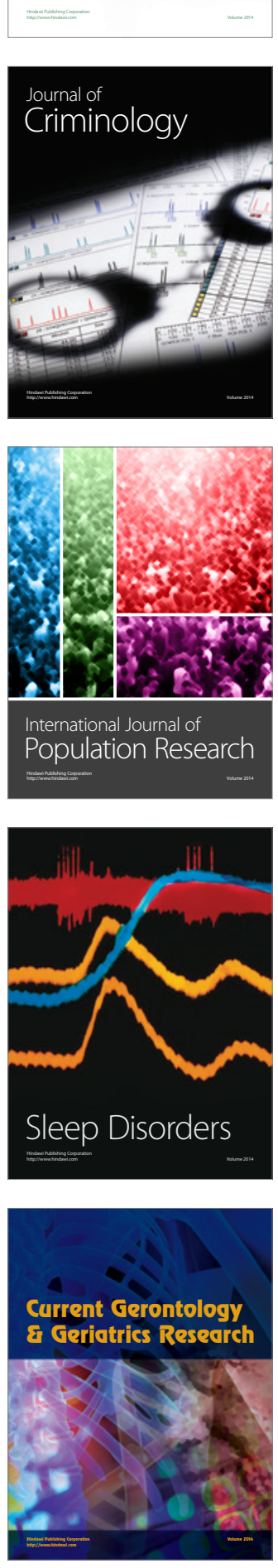
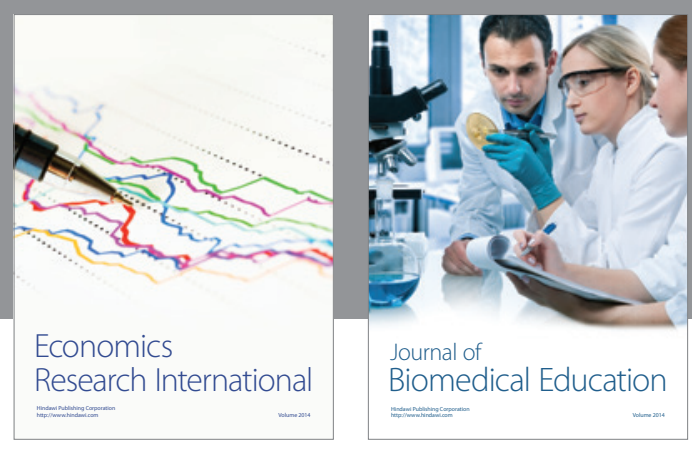

Journal of

Biomedical Education

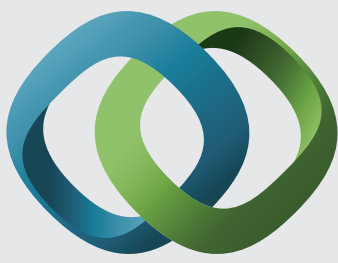

\section{Hindawi}

Submit your manuscripts at

http://www.hindawi.com
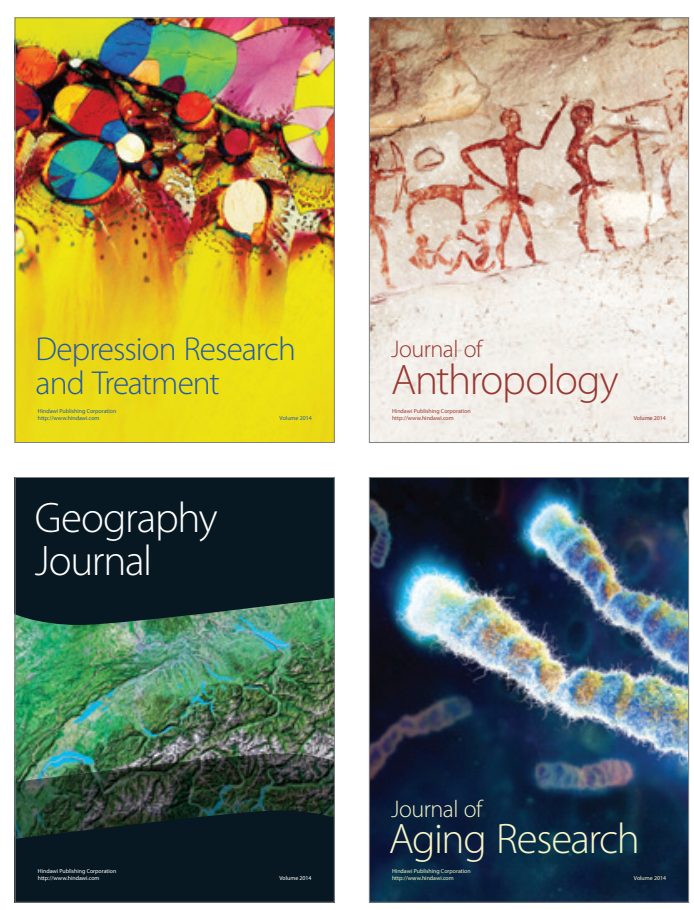

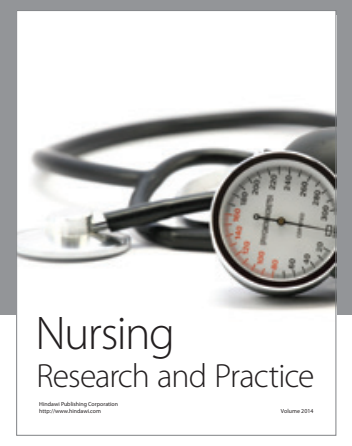

Nursing

Research and Practice

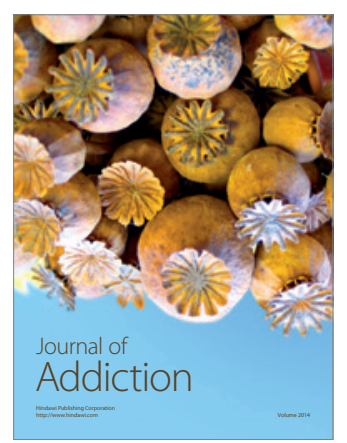

Child Development

Research

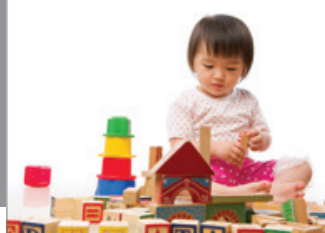

迥
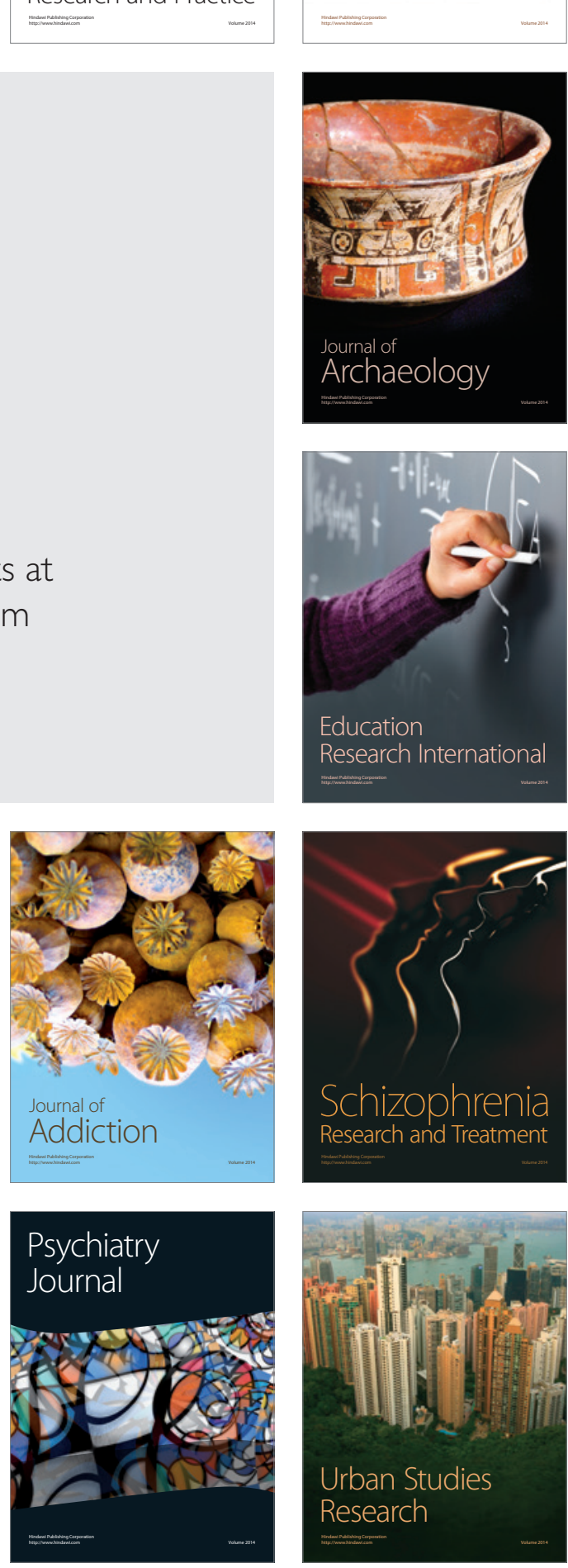